\title{
Immunochemotherapy in American Cutaneous Leishmaniasis: Immunological Aspects before and after Treatment
}

\author{
VPCP Toledo, W Mayrink*, KJ Gollob**, MAP Oliveira**, CA da Costa, \\ O Genaro**, JA Pinto***, LCC Afonso****/+
}

\begin{abstract}
Departamento de Análises Clínicas e Toxicológicas, Faculdade de Farmácia *Departamento de Parasitologia **Departamento de Bioquímica e Imunologia, Instituto de Ciências Biológicas ***Departamento de Pediatria, Faculdade de Medicina, Universidade Federal de Minas Gerais, Belo Horizonte, MG, Brasil *****Departamento de Ciências Biológicas/Nupeb, Instituto de Ciências Exatas e Biológicas, Universidade Federal de Ouro Preto,

Campus Universitário, Morro do Cruzeiro, 35400-000 Ouro Preto, MG, Brasil
\end{abstract}

In this study, we evaluated the immune response of patients suffering from cutaneous leishmaniasis treated with two distinct protocols. One group was treated with conventional chemotherapy using pentavalent antimonium salts and the other with immunochemotherapy where a vaccine against cutaneous leishmaniasis was combined with the antimonium salt. Our results show that, although no differences were observed in the necessary time for complete healing of the lesions between the two treatments, peripheral blood mononuclear cells from patients treated by chemotherapy showed smaller lymphoproliferative responses at the end of the treatment than those from patients in the immunochemotherapy group. Furthermore, IFN- $\gamma$ production was also different between the two groups. While cells from patients in the chemotherapy group produced more IFN- $\gamma$ at the end of treatment, a significant decrease in this cytokine production was associated with healing in the immunochemotherapy group. In addition, IL-10 production was also less intense in this latter group. Finally, an increase in $C D 8+-I F N-\gamma$ producing cells was detected in the chemotherapy group. Together these results point to an alternative treatment protocol where healing can be induced with a decreased production of a potentially toxic cytokine.

Key words: leishmaniasis - immunochemotherapy - human - interferon- $\gamma$

Cutaneous leishmaniasis is caused by a protozoa from the genus Leishmania that infect macrophages from many mammals including humans. The disease, depending on the species of the parasite, is characterized by occurrence of ulcerative lesions in the skin and/or mucosae that frequently result in permanent disfiguration of the patient. According to the World Health Organization, 12 million people in 88 countries are currently affected by the various forms of the disease, with an incidence of 1-1.5 million new cases per year. Treatment of leishmaniasis is based, primarily, on the administration of antimonium salts which, due to

Financial support: UNDP/World Bank/WHO Special Programme for Research and Training in Tropical Diseases (TDR), CNPq, Finep/CNPq/Pronex, Biobrás SA and Universidade Federal de Ouro Preto.

${ }^{+}$Corresponding author. Fax: +55-31-559.1680. E-mail: afonso@cpd.ufop.br

Received 31 January 2000

Accepted 5 September 2000 their toxicity (WHO 1990), may not be used in several cases. This fact, associated with the occurrence of resistance to treatment (Marsden 1985, Grogl et al. 1992), has increased the search for new alternative therapies.

A vaccine against cutaneous leishmaniasis developed by Mayrink et al. (1979) has been used not only in the prevention of the disease (Mayrink et al. 1985, 1986, Antunes et al. 1986, Nascimento et al. 1990) but also as an immunotherapeutic agent in cases where the antimonium salts can not be used (Mayrink et al. 1992, Hermeto et al. 1994), confirming the results of Convit et al. (1987) who used a different promastigote antigen preparation in association with BCG. This protocol, although highly successful, had the caveat of being substantially longer than conventional chemotherapy with antimonium salts. An attempt to reduce the treatment period was made by combining antimonium and vaccine administration (Genaro et al. 1996). This study showed that the combined therapy was able to reduce the time necessary for complete healing of the lesions when compared to conventional chemotherapy. 
Several studies have demonstrated that there is an important immunological component in the response to treatment with antimonials (Berger \& Fairlamb 1992, Coutinho et al. 1996, 1998). Murray et al. (1989) demonstrated that T cell-deficient mice were unable to control $L$. donovani proliferation when treated with Pentostam ${ }^{\circledR}$, suggesting that these cells (probably through cytokine production) are involved in the healing process following treatment. In humans, CD8+ T cells are, apparently, involved in the healing process and elevated IFN- $\gamma$ production at the end of the treatment has also been shown (da Cruz et al. 1994a). Furthermore, immunocompromised patients have been shown to be refractory to conventional chemotherapy, at least in some cases of visceral leishmaniasis (Peters et al. 1990).

Our main objective in this study was to understand the immunological aspects involved in the healing process associated with an alternative protocol based on the combined action of Glucantime ${ }^{\circledR}$ and a vaccine against cutaneous leishmaniasis (Leishvacin $\left.{ }^{\circledR}\right)$. The results described here, although not showing the same efficacy as previous trials, present an intriguing aspect regarding the immune mechanism underlying the healing process. The immune mechanism involved in the healing process was probably different in each treatment, since cells from patients treated by the combined therapy produced significantly less IFN- $\gamma$ in vitro than those from patients treated by the conventional protocol.

\section{MATERIALS AND METHODS}

Antimonial and vaccine - Glucantime ${ }^{\circledR}$ Rhodia Farma Ltda. (SP, Brazil) - was used as provided, in $5 \mathrm{ml}$ ampoules containing $425 \mathrm{mg}$ of meglumine antimoniate. Leishvacin ${ }^{\circledR}$ - Biobrás S.A. (Montes Claros, MG, Brazil) - was prepared, under Good Manufacturing Procedures (GMP), as a concentrate containing $240 \mu \mathrm{g} / \mathrm{ml}$ total nitrogen of killed promastigotes from five different Leishmania strains diluted in phosphate buffer $0.1 \mathrm{M}$ $\mathrm{pH} 7.4$, with timerosal phosphate $0.01 \%$ as a preservative (Mayrink et al. 1979). Staphylococcus aureus Cowan strain - SAC - (Calbiochem, La Jolla, CA, USA) was used at a concentration of $0.01 \%$ to stimulate IL-10 production by peripheral blood mononuclear cells (PBMC).

Antigen for immunological assays - L. V. braziliensis (MHOM/BR/2903) stationary phase promastigotes (seven days) were harvested from LIT medium (Camargo 1964), washed three times in sterile PBS by centrifugation at $1,000 \mathrm{x} g$ for 10 min at $4^{\circ} \mathrm{C}$. Cells were disrupted by three cycles of sonication $1 \mathrm{~min}, 20 \mathrm{~Hz}$ (Ultrasonic Disrupter, Tekmar Co., Cincinnati, OH). The suspension was sedimented at 4,000 $\mathrm{x} \mathrm{g}$ for $10 \mathrm{~min}$ and the supernatant collected for use as antigenic stimulus after protein quantification (Lowry et al. 1951). Aliquots $(1 \mathrm{mg} / \mathrm{ml})$ were stored at $-70^{\circ} \mathrm{C}$ until needed.

Study subjects - A total of 117 patients suffering from cutaneous leishmaniasis volunteered to take part in the trial. Written consent was obtained from the volunteers or from parents/guardians of those under 18 years of age. Patients were diagnosed on basis of clinical and parasitological criteria. Patients included in the trial patients were older than five years and had the cutaneous form of the disease with confirmed diagnostic. Pregnant women or those with debilitating diseases were not included in the trial as well as those who refused to sign the informed consent. The study protocols were in accordance with The Helsinki Declaration and has been approved by the Ethical Committee from the Escola de Medicina, Universidade Federal de Minas Gerais.

Treatment protocols - The study was designed as a double blinded randomized trial. Based on previous non-randomized trials (Genaro et al. 1996) and estimating an $\alpha$ value of 0.01 (type I error) and a $\beta$ value of 0.05 (type II error) a sample size of 50 volunteers per group was calculated for the trial, including a 10\% chance of withdrawal. Patients were allocated at a 1:1 ratio into two groups. Both groups received i.m. injections of Glucantime ${ }^{\circledR}$ at daily doses of $1 \mathrm{ml} / 5 \mathrm{~kg}$ body weight, until a maximum dose of $10 \mathrm{ml} /$ day. Patients treated by immunochemotherapy (IC) received simultaneous subcutaneous injections of vaccine in the forearm, according to the following protocol (Mayrink et al. 1991): day 1: $100 \mu \mathrm{l}$; day 2: $200 \mu \mathrm{l}$; day 3: $300 \mu \mathrm{l}$; day 4: $400 \mu \mathrm{l}$ and days 5 to $10: 500 \mu \mathrm{l}$. After a resting period of 10 days another series of antimonial and vaccine injections (day 1 to 10: $500 \mu \mathrm{l}$ ) was administered. This treatment/rest/treatment protocol was maintained until complete healing of lesions. The control group $(\mathrm{CH})$ received, besides Glucantime ${ }^{\circledR}$, placebo injections (sterile PBS with $0.01 \%$ timerosal phosphate) in the forearm according to the same protocol described for the previous group. The occurrence of adverse reactions was monitored along the treatment period. No report of adverse reaction was filed in both treatment groups during the whole trial.

Montenegro's skin test - The Montenegro's skin test was performed as previously described (da Costa et al. 1996) using a standardized antigen preparation. Briefly, $4 \mu \mathrm{g}(0.1 \mathrm{ml})$ of antigen was injected intradermally into the forearm. Readings were performed $48 \mathrm{~h}$ after injection. Reactions were considered positive if presence of induration at the site of injection was detected. 
Lymphocyte proliferation assays - This assay was performed as previously described (Mendonça et al. 1986). Briefly, PBMC were isolated from blood samples by centrifugation over a FicollHypaque gradient. $3.5 \times 10^{6}$ cells were stimulated in RPMI medium supplemented with 5\% human $\mathrm{AB}$ serum for $24 \mathrm{~h}$ with $0.1 \mu \mathrm{g}$ Phytohemaglutinin A (PHA) or with $10 \mu \mathrm{g}$ (protein content) of $L$. braziliensis antigen for $72 \mathrm{~h}$. Proliferation was assessed by incorporation of $\left[{ }^{3} \mathrm{H}\right]$-Thymidine (SIGMA, St. Louis, MO, USA, $5.3 \mathrm{Ci} / \mathrm{mmol}$ ) for the last $18 \mathrm{~h}$ of culture. Results were expressed as $\Delta \mathrm{kcpm}$ (kcpm of stimulated - $\mathrm{kcpm}$ of control cultures).

Cytokine production - Cytokine production was assayed on supernatants from PBMC (5 x $10^{6}$ cells/ $\mathrm{ml}$ ) stimulated with $50 \mu \mathrm{g} / \mathrm{ml}$ of $L$. braziliensis antigen. IL-2, was assayed on $24 \mathrm{~h}$ supernatants (Intertest 2, Genzyme Immunobiologicals, USA). IL-10 was assayed on $72 \mathrm{~h}$ supernatants (Quantikine Human IL-10 Immunoassay, R \& D systems, USA). All tests were performed according to manufacturer's instructions. IL-12 and IFN- $\gamma$ assays were performed on 24 and $72 \mathrm{~h}$ supernatants, respectively, according to the protocols described below.

$I F N-\gamma$ ELISA assay - IFN- $\gamma$ production was measured in three day culture supernatants by a sandwich ELISA. Plates were coated with a mouse monoclonal antibody (B133.1 - a kind gift from Dr Giorgio Trinchieri, The Wistar Institute, Philadelphia, PA, USA) at $5 \mu \mathrm{g} / \mathrm{ml}$ in $0.1 \mathrm{M} \mathrm{NaHCO}_{3} /$ $\mathrm{NaCO}_{3}$ buffer, $\mathrm{pH} 8.6$, overnight at $4^{\circ} \mathrm{C}$. After blocking with phosphate buffered saline (PBS)/5\% bovine fetal serum (BFS) for $1 \mathrm{~h}$, plates were washed three times with PBS/Tween $200.05 \%$. Samples were added directly to the plate and incubated for $2 \mathrm{~h}$ at $37^{\circ} \mathrm{C}$. Standard curve was performed using recombinant human IFN- $\gamma$ diluted in $\mathrm{PBS} / 5 \% \mathrm{BFS}$ at concentrations which varied from 12.5 to $0.02 \mathrm{ng} / \mathrm{ml}$. After washing, plates were incubated with biotinylated-B133.5 monoclonal antibody, at a concentration of $0.5 \mu \mathrm{g} / \mathrm{ml}$, for $1 \mathrm{~h}$. This incubation was followed by washing and incubation with streptoavidin-peroxidase for another hour. ABTS (SIGMA - $0.5 \mathrm{mg} / \mathrm{ml}$ ) and hydrogen peroxide $(0.01 \%)$ were used as substrates. Readings were performed at $415 \mathrm{~nm}$.

IL-12 ELISA assay - IL-12 p40 detection was carried out by a ELISA sandwich using mouse anti human IL-12 p40 monoclonal antibodies (C11.15 and biotinylated-C8.6). The same procedure and concentrations described above were used in this assay.

Flow cytometry analysis - PBMC were collected before and after treatment and stimulated in vitro with L. braziliensis. After $72 \mathrm{~h}, 2 \times 10^{6}$ cells were harvested, washed in sterile PBS and stained with anti-CD3-FITC, and rodamine labeled antiCD4 or anti-CD8 monoclonal antibodies (BecktonDickson, San Jose, CA, USA). Cytometric analysis was performed on a Coulter - EPICS $751 \mathrm{cy}-$ tometer and data analyzed by the LYSIS II software. A minimum of 30,000 events were analyzed per sample.

IFN- $\gamma$ intracellular staining - PBMC were stimulated in vitro with L. braziliensis for $72 \mathrm{~h}$. Brefeldin A $(1 \mathrm{mg} / \mathrm{ml})$ was added during the last 6 $\mathrm{h}$ of culture. Cells were harvested and stained for CD4 or CD8 markers as described above and then washed with PBS $/ 0.02 \%$ sodium azide $/ 0.2 \%$ bovine soroalbumin. Cells were then fixed with $2 \%$ paraformaldehyde and washed again. Aliquots of $2 \times 10^{6}$ permeabilized cells $(50 \mu \mathrm{l})$ were incubated with FITC labeled anti-human IFN- $\gamma$ monoclonal antibody (Pharmingen, San Diego, CA, USA), washed and analyzed by flow cytometry immediately after (Prussin \& Metcalfe 1995).

Statistical analysis - Analysis of patient distribution between groups was made by univariated analysis. Laboratorial data were analyzed by paired two tail Student's t test, regression analysis and correlation. $\mathrm{p}$ values $\leq 0.05$ were considered significant.

\section{RESULTS}

Demographic and clinical data - A total of 117 patients involved in this study were allocated to the two treatment groups on a 1:1 ratio. Demographic data obtained from the two groups showed that they were homogenous in regard to age [30.1 \pm 13.4 and $26.2 \pm 17.6$ years for the chemotherapy $(\mathrm{CH})$ and immunochemotherapy (IC) groups, respectively] and sex (53.1\% male - $\mathrm{CH}$ and $54.7 \%$ male - IC). Clinical data regarding the leishmanial infection were also similar between the two groups (Table). Patients from the two groups had lesions that were similar in evolution time, size and number. It is important to mention that the majority of the patients (76\%) presented only one well defined lesion, usually in an uncovered part of the limbs. Both groups also presented similar rates of positive Montenegro's skin test prior to treatment. Although patients in the IC group presented a tendency to heal faster, no statistical differences were observed between the two groups when healing rate was measured by the number of treatment series necessary to induce complete healing of the lesions. It should be emphasized, however, that regardless of the treatment adopted, complete healing of the lesions was always obtained at the end of treatment.

Lymphoproliferative responses - In order to evaluate the cellular immune response that was 
associated to each treatment, PBMC obtained from blood samples taken before treatment, after two series and one month after the end of treatment were stimulated in vitro with Leishmania antigen. While cells from uninfected volunteers did not proliferate in response to the antigenic stimulus, proliferative responses, measured five days after stimulation, varied significantly among the patients in both treatment protocols (Fig. 1). Nonetheless, it was possible to observe that in the $\mathrm{CH}$ group there was a decrease in the mean proliferative response after the end of treatment $(\Delta \mathrm{kcpm}=10.4 \pm 10.0$ mean $\pm \mathrm{SD}$ ) as compared to results observed before treatment $(\Delta \mathrm{kcpm}=18.2 \pm 26.2, \mathrm{p}<0.05)$. On the hand, no alteration in lymphoproliferation was observed within the IC group, with mean $\Delta \mathrm{kcpm}$ values remaining practically constant during the whole treatment period (before treatment $13.3 \pm 10.7$; after treatment $21.3 \pm 35.2, \mathrm{p}>0.05$ ).

Cytokine production by stimulated PBMC - The role of cytokines in the control of leishmaniasis has been clearly demonstrated in many animal models as well as in the human disease (for review see Scott 1989, Kemp 1997, Etges \& Müller 1998). We initially investigated the role of IL-2 during both treatment protocols by measuring its levels in culture supernatants from antigen stimulated PBMC. Fig. 2 shows the results obtained before and after treatment in both groups. While no differences were observed in the $\mathrm{CH}$ group, cells from patients from the IC group produced significantly more IL-2 after treatment than they did before treatment $(\mathrm{p}<0.05)$. As expected, no significative differences were observed between the treatment groups before treatment onset ( $p>0.05$ ).

Elimination of Leishmania amastigotes from lesions has been shown to be dependent on IFN- $\gamma$ production by $\mathrm{T}$ lymphocytes as well as by NK cells (Locksley et al. 1987, Heinzel et al. 1991, Scott 1991, Scharton \& Scott 1993, Scott \& Trinchieri 1995). We decided to investigate whether the different treatments would interfere with IFN- $\gamma$ production, and thus alter the healing process. To indirectly assess this hypothesis we

TABLE I

Clinical characteristics of patients submitted to chemotherapy or immunochemotherapy

\begin{tabular}{lcc}
\hline & \multicolumn{2}{c}{ Treatment } \\
\cline { 2 - 3 } & $\begin{array}{c}\text { Chemotherapy } \\
(\mathrm{n}=64)\end{array}$ & $\begin{array}{c}\text { Immunochemotherapy } \\
(\mathrm{n}=53)\end{array}$ \\
\hline Lesion evolution before treatment onset (days) & $99.3 \pm 167.5^{a}$ & $72.1 \pm 52.9$ \\
Number of lesions & $1.8^{a} \pm .^{a}$ & $1.7 \pm 1.5$ \\
Positive skin test (\%) & $55^{a}$ & 48 \\
Number of treatment series necessary for complete healing & $4.2^{a} \pm 1.7^{a}$ & $3.7 \pm 1.4$ \\
\hline
\end{tabular}

Values represent mean $\pm 1 \mathrm{SD} ; a: \mathrm{p}>0.05$

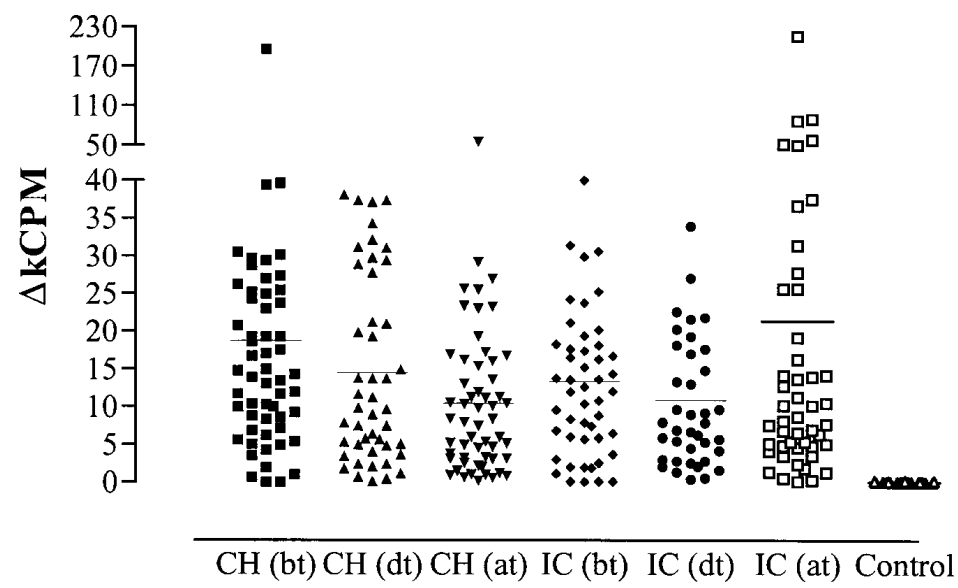

Fig. 1: lymphoproliferative responses of antigen stimulated peripheral blood mononuclear cells (PBMC) from patients submitted to chemotherapy or immunochemotherapy. Symbols represent $\Delta \mathrm{kcpm}$ (cpm stimulated cultures - cpm control cultures) for each individual before treatment onset (bt), after the second series of treatment (dt), and after complete healing of lesions (at). Horizontal bars represent the mean value for each group. Treatments $-\mathrm{CH}$ : chemotherapy; IC: immunochemotherapy; $\mathrm{n}=56$ $(\mathrm{CH})$ and 49 (IC); control cultures were performed using PBMC from healthy individuals living outside the endemic area. 


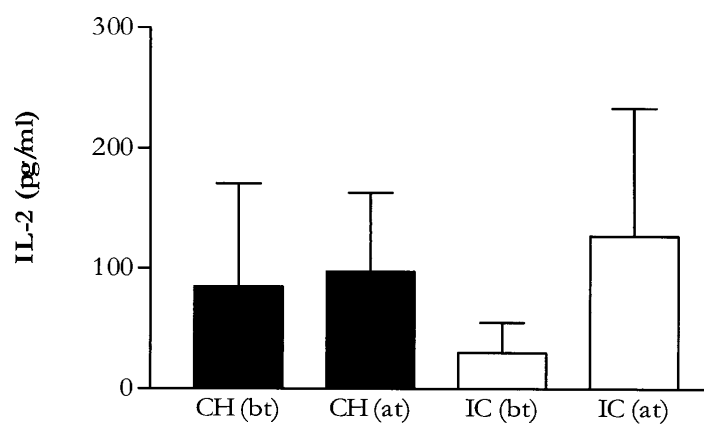

Fig. 2: IL-2 production by antigen-stimulated stimulated peripheral blood mononuclear cells. Bars represent mean value \pm 1 SD of IL-2 detected in supernatant of antigen stimulated cultures from patients at different times points. (bt): before treatment; (at): after complete healing of lesions. Treatments $\mathrm{CH}$ : chemotherapy; IC: immunochemotherapy; $\mathrm{n}=11(\mathrm{CH})$ and 10 (IC)

measured the production of this cytokine in culture supernatants of stimulated PBMC. As expected, no differences were observed between the two treatment groups before initiation of treatment (Fig. 3). As previously observed (da Cruz et al. 1994a), there was an increase in IFN- $\gamma$ production by PBMC after treatment in the group treated with Glucantime ${ }^{\circledR}$ alone $(1616 \pm 296 \mathrm{pg} / \mathrm{ml}$ versus 1055 $\pm 193 \mathrm{pg} / \mathrm{ml}$ before treatment, $\mathrm{p}<0.05$ ), with no differences being detected after two series of treatment. Interestingly, however, supernatants from cultures from patients treated by immunochemotherapy presented a decreased IFN- $\gamma$ production at the end of treatment when compared to values before treatment $(1095 \pm 245 \mathrm{pg} / \mathrm{ml}$ before treatment versus $860 \pm 227$ after treatment, $\mathrm{p}<0.05$ ).
IL-12 stimulates IFN- $\gamma$ production by NK and T cells (Heinzel et al. 1991, Prussin \& Metcalfe 1995) and is involved in resistance to infection by Leishmania (Heinzel et al. 1993, Afonso et al. 1994, Nabors et al. 1995, Bacellar et al. 1996, Mattner et al. 1996). When PBMC were stimulated in vitro with $L$. braziliensis antigen, production of this cytokine was not detected (data not shown) regardless of treatment protocol or treatment period. To further investigate the production of IL-12, we measured the IFN- $\gamma$ production in the presence of C8.6, a neutralizing monoclonal antibody directed against the p40 chain of IL-12 (Fig. 4). We were able to show that, in the $\mathrm{CH}$ group, cultures treated with the monoclonal antibody showed a reduction in IFN$\gamma$ production to $54.6 \pm 31.8 \%$ of the control cultures

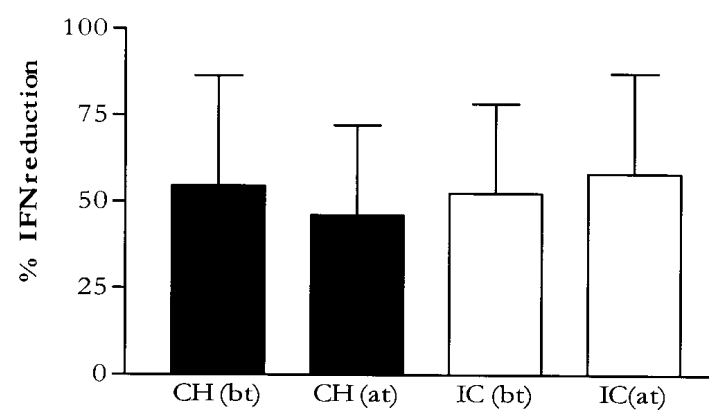

Fig. 4: IL-12 dependent IFN- $\gamma$ production by antigen-stimulated peripheral blood mononuclear cells (PBMC). PBMC were stimulated for $72 \mathrm{~h}$ with antigen in the presence or absence of an anti-IL-12 p40 neutralizing monoclonal antibody (C8.6). Bars represent the mean percentage $\pm 1 \mathrm{SD}$ of the reduction in IFN- $\gamma$ production in cultures with the antibody as compared to cultures without IL-12 inhibition. (bt): before treatment; (at): after complete healing of lesions. Treatments $\mathrm{CH}$ : chemotherapy; IC: immunochemotherapy

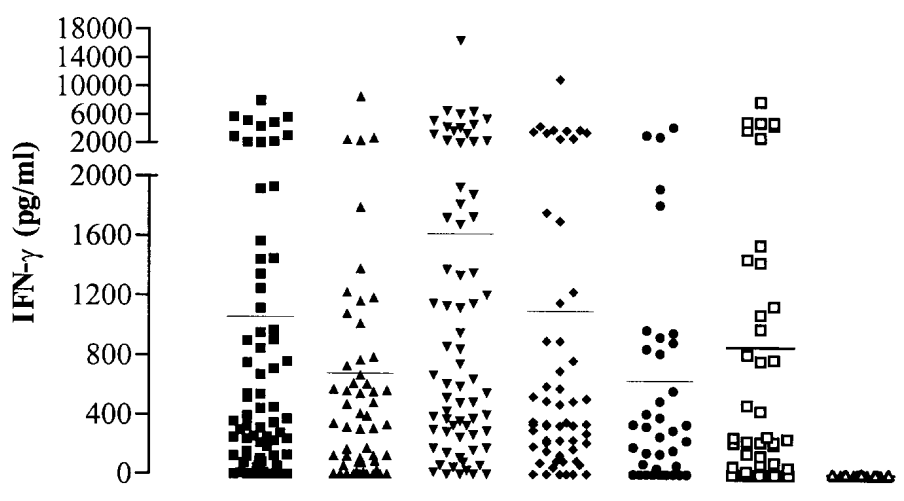

$\mathrm{CH}(\mathrm{bt}) \mathrm{CH}$ (dt) $\mathrm{CH}$ (at) IC (bt) IC (dt) IC (at) Contol

Fig. 3: IFN- $\gamma$ production by stimulated peripheral blood mononuclear cells (PBMC) increases with chemotherapy but decreases in patients treated by immunochemotherapy. Symbols represent cytokine production by cells stimulated with Leishmania antigen for $72 \mathrm{~h}$ for each individual before treatment (bt), after the second series of treatment (dt), and after complete healing of lesions (at). Control cultures were made using PBMC from healthy individuals living outside the endemic area. Horizontal bars represent the mean value for each group. Treatments - CH: chemotherapy; IC: immunochemotherapy; $n=64$ (CH) and 53 (IC) 
before treatment and $46 \pm 26 \%$ after treatment. A similar reduction was observed in the IC group, in which IFN- $\gamma$ production was reduced to $53 \pm 25.8 \%$ of the control culture before treatment and $58 \pm 28 \%$ after treatment. No statistical differences were detected in the reduction rates among groups. These results indicate that, although we were not able to detect IL-12 production in the supernatant, this cytokine was being produced and was responsible, at least partially, for the IFN- $\gamma$ detected.

Another cytokine involved in the control of leishmaniasis is IL-10. This cytokine downregulates Th1 type responses thus preventing proper healing. Thus, it was of interest to investigate whether IL-10 was being produced in cultures from patients treated by the two different protocols. The results shown in Fig. 5 indicate that a significant decrease in IL-10 production could be observed in both treatment protocols already after the second series of treatment, persisting until the end of treatment. Interestingly, IL-10 production at the end of treatment in the IC group $(5.7 \pm 13.2 \mathrm{pg} / \mathrm{ml})$ was statistically lower than in the $\mathrm{CH}$ group (26.7 $\pm 32.1 \mathrm{pg} / \mathrm{ml})(\mathrm{p}<0.05)$.

Since the main difference in the two treatment protocols is the addition of Leishmania antigen, we decided to investigate whether this antigen could inhibit IL-10 production by PBMC stimulated with SAC. As shown in Fig. 6, when Leishmania antigen was added to cultures stimulated with SAC a dose dependent decrease in IL-10 production was observed in two out of three patients tested, suggesting that antigen inoculation during treatment may have contributed to the lower level of IL-10 detected in the supernatants of patients treated by immunochemotherapy.
Phenotypic characterization of the antigen-responding cells - Stimulated PBMC were analyzed by flow cytometry after three days in culture. Cells from untreated patients showed a predominance of CD4+ T cells as measured by a positive CD4/ CD8 ratio (Fig. 7). This ratio decreased after treatment in both $\mathrm{CH}$ and IC groups with no significant difference between the two groups, indicating an increase in the stimulation of CD8+ T cells in culture as the treatment lead to healing of the lesions.

In order to further characterize the IFN- $\gamma$ production in stimulated PBMC cultures, cells were double-stained for intracellular IFN- $\gamma$ production and

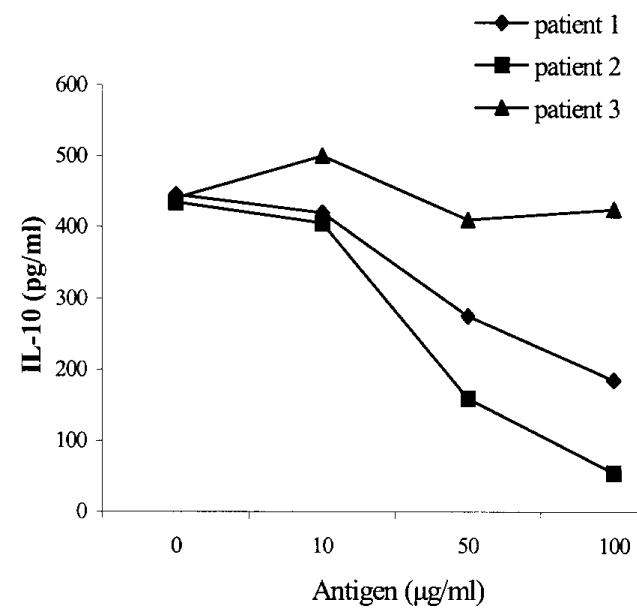

Fig. 6: Leishmania antigen decreases IL-10 production by SAC-stimulated peripheral blood mononuclear cells (PBMC). PBMC from patients with active lesions (before treatment) were stimulated with SAC in the presence of increasing concentrations of Leishmania antigen for $72 \mathrm{~h}$. Values are representative of each individual. Cultures were done in duplicates.

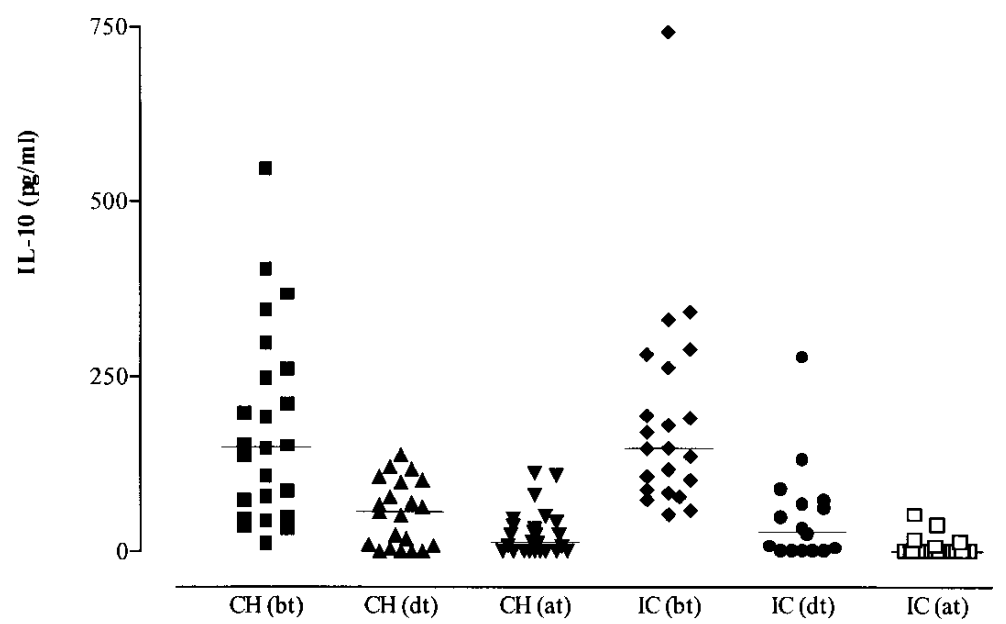

Fig. 5: IL-10 production by antigen-stimulated peripheral blood mononuclear cells from patients decreases with treatment. Symbols represent cytokine production by cells stimulated with Leishmania antigen for $72 \mathrm{~h}$ for each individual before treatment onset (bt), after the second series of treatment (dt), and after complete healing of lesions (at). Bars represent the mean value for each group $\pm 1 \mathrm{SD}$. Treatments - $\mathrm{CH}$ : chemotherapy; IC: immunochemotherapy; $\mathrm{n}=25(\mathrm{CH})$ and 22 (IC) 


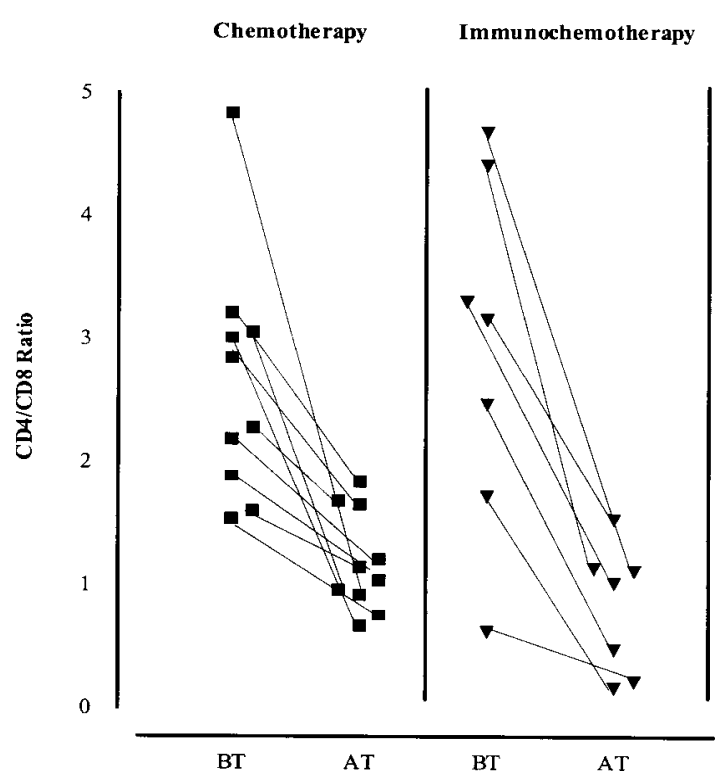

Fig. 7: phenotypic characterization of stimulated $\mathrm{T}$ cells before and after treatment. Peripheral blood mononuclear cells were stimulated with Leishmania antigen for $72 \mathrm{~h}$. Cells were collected and analyzed by flow cytometry for CD3, CD4 and CD8 markers. Symbols represent data from each patient at different time points. (BT): before treatment; (AT): after complete healing of lesions

surface markers. As shown in Fig. 8, a small percentage of both CD4+ and CD8+ cells were producing IFN- $\gamma$ before treatment was initiated, both in the IC and the $\mathrm{CH}$ groups. At the end of treatment, however, cytometric analysis of stimulated cells from patients in the $\mathrm{CH}$ group showed an increased percentage of IFN- $\gamma$ producing cells. This increase in IFN- $\gamma$ production was particularly noted in the CD8+ population $(\mathrm{p}<0.05)$, although CD4+ IFN- $\gamma$ producing cells also showed a tendency to increase. On the contrary, no differences were detected in cells from patients belonging to the IC group. These results are in agreement with the IFN$\gamma$ production in culture supernatants (Fig. 2).

\section{DISCUSSION}

Treatment against leishmaniasis is based primarily on the administration of antimonium salts via the intramuscular route during an extensive period of time. These salts, however, are expensive, present considerable toxicity, and require several injections under supervised administration. These facts justify the search for alternative treatment protocols that could reduce the amount of antimonium administered to the patient. In this study we compared the combined administration of Glucantime ${ }^{\circledR}$ and Leishvacin ${ }^{\circledR}$ to conventional chemotherapy in regard to several aspects including its efficacy, healing time, and, specially the immune response associated with each protocol.

A total of 117 patients participated in the study (63 on chemotherapy and 54 on immunochemotherapy) most of which had a single lesion usually located on the forearm or leg. Analysis of the patient's data demonstrated that both treatment groups were comparable as to the demographic distribution of the patients as well as the clinical characteristics of the disease, reflecting the proper randomization of the study protocol. In addition,

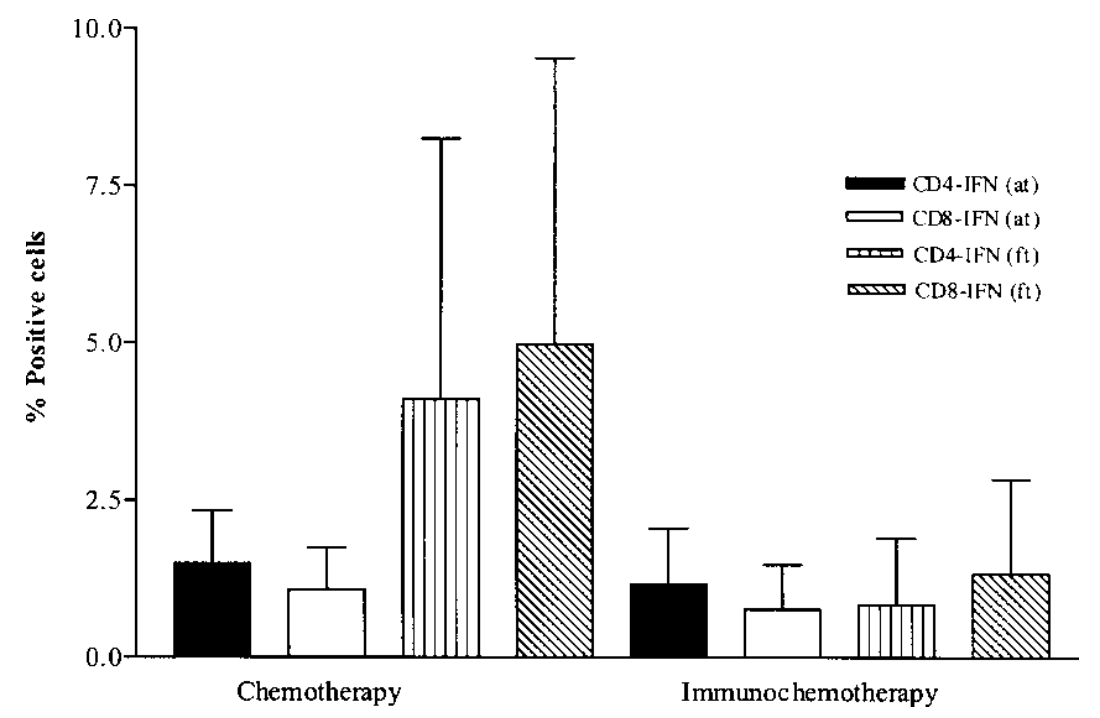

Fig. 8: characterization of IFN- $\gamma$ producing cells - peripheral blood mononuclear cells were stimulated for $72 \mathrm{~h}$ with Leishmania antigen and then incubated with Brefeldin A to allow for accumulation of IFN- $\gamma$. Cells were collected and double stained for IFN- $\gamma$ and CD4 or CD8 markers. Bars represent the mean value for each group \pm 1 SD. (bt): before treatment; (at): after complete healing of lesions; $n=10(\mathrm{CH})$ and 8 (IC) 
Montenegro's skin test were positive in $88 \%$ of the cases, supporting previous observations from our group as well as from other studies (Carvalho et al. 1995, da Costa et al. 1996), thus confirming the validity of this test as a helpful diagnostic tool in leishmaniasis.

Although no statistical differences were observed in the time required for healing between the two treatment protocols, it is important to mention that both protocols were successful in inducing complete healing in all patients involved in the study.

The proliferative response of lymphocytes stimulated with $L$. braziliensis was analyzed before, during and after the end of the treatment period. The great majority of patients presented a positive response to the stimulus. Patients treated with chemotherapy alone showed a decrease in the response at the end of the treatment, in accordance with results reported by others (da Cruz et al. 1994a). However, patients treated with immunochemotherapy showed a persistent lymphoproliferative response throughout the treatment. This difference in response to in vitro stimulation is probably related to the permanent presence of the antigen in vivo during the treatment. It is expected that in vivo stimulation of $T$ cells decreases as treatment progresses toward healing in patients treated with Glucantime ${ }^{\circledR}$ alone, since the reduction in the parasite load would probably lead to a decreased number of responsive T cells. In immunochemotherapy, however, the continual inoculation of Leishmania antigen may have kept these cells consistently stimulated in vivo even with a decreased parasite load. This was reflected by an unaltered in vitro response at the end of treatment. Also in agreement with previous studies (Convit et al. 1993, da Cruz et al. 1994a, Mendonça et al. 1995), no correlation between the intensity of the Montenegro's reaction and the in vitro proliferative response was observed.

As part of the evaluation of the immune response, we analyzed the production of several cytokines by stimulated PBMC. Our study focused primarily on the production of IFN- $\gamma$ by these cells due to the involvement of this cytokine in resistance to and recovery from leishmanial infections (Carvalho et al. 1995, Coutinho et al. 1998, Ribeirode-Jesus et al. 1998). When analyzing the production of this cytokine before treatment onset it was observed that cells from patients with chronic lesions produced more IFN- $\gamma$ than those from patients with recent infections. This fact has been reported previously (Ribeiro-de-Jesus et al. 1998) and is probably related to the elevated number of IFN- $\gamma$ producing $\mathrm{T}$ cells that infiltrate these lesions (Melby et al. 1994). Comparison of IFN- $\gamma$ production in supernatants of stimulated PBMC ob- tained at different time points during the course of the treatment, revealed a significant increase in IFN- $\gamma$ from patients that recovered from infection after conventional treatment as compared to before treatment. Again, this observation was in agreement with data previously reported (da Cruz et al. 1994a). This increased IFN- $\gamma$ production is probably associated with an increased expression of CD8+-IFN- $\gamma$ producing cells as shown in Figs 7 and 8 . On the other hand, in patients treated by immunochemotherapy, a marked decrease in IFN$\gamma$ production was observed when cultures from recovered patients were compared to those from the same patients before treatment.

The differences in IFN- $\gamma$ production at the end of the two protocols could not be related to differences in the production of IL-12. Although we were not able to detect IL-12 p40 in culture supernatants under the conditions used to stimulate the cells (data not shown), we indirectly demonstrated the presence of this cytokine through its ability to induce IFN- $\gamma$ production. Even though around 50\% of IFN- $\gamma$ production was dependent on the presence of IL-12 (Fig. 4), no differences in IL-12induced IFN- $\gamma$ production could be detected between the two experimental protocols.

IL-10 is involved in the downregulation of Th1 responses (Fiorentino et al. 1991, Mosmann \& Moore 1991, Howard \& O'Garra 1992, D'Andrea et al. 1993). As shown in Fig. 5, PBMC from infected patients produced significant levels of this cytokine before treatment. After therapy was initiated we observed a marked decrease in the production of this cytokine in both treatment protocols. The decreased production of IL-10 probably allowed for a more efficient action of IFN- $\gamma$, leading to healing of the lesions. It is interesting to observe that addition of Leishmania antigen to PBMC cultures stimulated with SAC decreased IL-10 production by these cells (Fig. 6). It is conceivable that in patients treated by immunochemotherapy the continuous administration of Leishmania antigen may have contributed to a greater decrease in IL-10 production in these patients (Fig 5). This could lead to a faster elimination of the parasites by IFN- $\gamma$-activated macrophages. Even though we did not detect a faster healing of the lesions in patients treated by immunochemotherapy we can not exclude the possibility that parasite elimination was faster in these patients. Moreover, it is also important to note that patients treated with the combined therapy were able to control disease progression even with a decreased IFN$\gamma$ production. Although this fact could reflect in a lower degree of post-treatment protection, that would lead to lesion relapse or reinfection, no such occurrences were observed both in this and in previous studies (data not shown). 
The search for alternative protocols for treatment of leishmaniasis is justified by the increase in the number of cases of resistance to conventional chemotherapy. Thus, Cunha et al. (1994) used the protocol described here to successfully treat five HIV+ patients with cutaneous leishmaniasis, four of which were resistant to conventional antimonium therapy and one to antimonium and Amphotericin B. In another study, an HIV+ patient with disseminated cutaneous leishmaniasis resistant to antimonial therapy showed a significant improve in lymphoproliferative response and IFN$\gamma$ production after treatment and successful healing of over 250 lesions (da Cruz et al. 1994b). This protocol offers an alternative treatment to cutaneous leishmaniasis cases where conventional chemotherapy is not effective justifying the increased cost of adding the vaccine to the treatment. Further studies should better clarify the mechanisms associated with this therapeutic protocol.

\section{ACKNOWLEDGEMENTS}

To Dr Evaldo Nascimento for access to the flow cytometer facility, Mr Jair Cecílio de Paula for technical assistance, Dr Ivan BM Sampaio for assistance with the statistical analysis, and Dr Leda Q Vieira for carefully reviewing the manuscript.

\section{REFERENCES}

Afonso, LCC, Scharton TM, Vieira LQ, Wysocka M, Trinchieri G, Scott P 1994. The adjuvant effect of Interleukin-12 in a vaccine against Leishmania major. Science 263: 235-237.

Antunes CMF, Mayrink W, Magalhães PA, Costa CA, Melo MN, Michalick MSM, Williams P, Oliveira Lima A, Vieira JBF, Schettini APM 1986. Controlled field trials of a vaccine against New World cutaneous leishmaniasis. Int J Epidemiol 15: 572-580.

Bacellar O, Brodskyn C, Guerreiro J, Barral-Netto M, Costa CH, Coffman RL, Johnson WD, Carvalho EM 1996. Interleukin-12 restores interferon-gamma production and cytotoxic responses in visceral leishmaniasis. J Infect Dis 173: 1515-1518.

Berger BJ, Fairlamb AH 1992. Interactions between immunity and chemotherapy in the treatment of the trypanosomiases and leishmaniases. Parasitology 105 (Suppl.): S71-S78.

Camargo EP 1964. Growth and differentiation in Trypanosoma cruzi. I. Origin of metacyclic trypanosomes in liquid medium. Rev Inst Med Trop São Paulo 6: 43-100.

Carvalho EM, Correia FD, Bacellar O, Almeida RP, Lessa H, Rocha H 1995. Characterization of the immune response in subjects with self-healing cutaneous leishmaniasis. Am J Trop Med Hyg 53: 273-277.

Convit J, Castellano PL, Rondón AJ, Pinardi ME, Ulrich M, Castés M, Bloom B, Garcia L 1987. Immunotherapy versus chemotherapy in localized cutaneous leishmaniasis. Lancet 1: 401-405.

Convit J, Ulrich M, Fernandez CT, Tapia FJ, Caceres-
Dittmar G, Castes M, Rondon AJ 1993. The clinical and immunological spectrum of American cutaneous leishmaniasis. Trans $R$ Soc Trop Med Hyg 87: 444-448.

Coutinho SG, da-Cruz AM, Bertho AL, Santiago MA, de Luca P 1998. Immunologic patterns associated with cure in human American cutaneous leishmaniasis. Braz J Med Biol Res 31: 139-142.

Coutinho SG, Oliveira MP, da Cruz AM, de Luca PM, Mendonça SC, Bertho AL, Soong L, McMahon-Pratt D 1996. T-cell responsiveness of American cutaneous leishmaniasis patients to purified Leishmania pifanoi amastigote antigens and Leishmania braziliensis promastigote antigens: immunologic patterns associated with cure. Exp Parasitol 84: 144155.

Cunha RMC, Hallack KA, Mayrink W 1994. Leishmaniose disseminada em paciente infectado pelo vírus HIV. Evolução clínico-morfológica atípica. Rev Soc Bras Med Trop 27: 389-401.

D’Andrea A, Aste-Amezaga M, Valiante NM, Ma X, Kubin M, Trinchieri G 1993. Interleukin-10 inhibits human lymphocyte IFN- $\gamma$ production by suppressing natural killer cell stimulatory factor/interleukin12 synthesis in accessory cells. J Exp Med 178: 10411048.

da Costa CA, Toledo VPCP, Genaro O, Williams P, Mayrink W 1996. Montenegro skin test-evaluation of the composition and stability of the antigen preparation. Mem Inst Oswaldo Cruz 91: 193-194.

da Cruz AM, Conceição-Silva F, Bertho AL, Coutinho S 1994a. Leishmania - Reactive CD4+ and CD8+ T cells associated with cure of human cutaneous leishmaniasis. Infect Immun 62: 2614-2618.

da Cruz AM, Mayrink W, Filgueiras D, Coutinho S 1994b. Imunoquimioterapia em um paciente com leishmaniose mucocutânea e SIDA: Estudos imunológicos. Rev Soc Bras Med Trop 27: 388389.

Etges R, Müller I 1998. Progressive disease or protective immunity to Leishmania major infection: the result of a network of stimulatory and inhibitory interactions. J Mol Med 76: 372-390.

Fiorentino DF, Zlotnik A, Vieira P, Mosmann TR, Howard M, Moore KW, O'Garra A 1991. IL-10 acts on the antigen-presenting cell to inhibit cytokine production by Th1 cells. J Immunol 146: 3444-3451.

Genaro O, Toledo VPCP, Costa CA, Hermeto MV, Afonso LCC, Mayrink W 1996. Vaccine for prophylaxis and immunotherapy, Brazil. Clin Dermatol 14: 503-512.

Grogl M, Thomason TN, Franke ED 1992. Drug resistance in leishmaniasis: its implication in systemic chemotherapy of cutaneous and mucocutaneous disease. Am J Trop Med Hyg 47: 117-126.

Heinzel FP, Sadick MD, Mutha SS, Locksley RM 1991. Production of interferon $\gamma$, interleukin 2, interleukin 4 , and interleukin 10 by $\mathrm{CD} 4^{+}$lymphocytes in vivo during healing and progressive murine leishmaniasis. Proc Natl Acad Sci USA 88: 7011-7015.

Heinzel FP, Schoenhaut DS, Rerko RM, Rosser LE, Gately MK 1993. Recombinant interleukin 12 cures 
mice infected with Leishmania major. J Exp Med 177: 1505-1509.

Hermeto MV, Vieira-Dias D, Genaro O, Rotondo-Silva A, da Costa CA, Toledo VPCP, Michalick MSM, Williams P, Mayrink W 1994. Outbreak of cutaneous leishmaniasis in the Rio Doce Valley, Minas Gerais, Brazil. Mem Inst Oswaldo Cruz 89: 519-521.

Howard M, O'Garra A 1992. Biological properties of interleukin 10. Immunol Today 113: 198-200.

Kemp M 1997. Regulator and effector functions of Tcell subsets in human Leishmania infections. APMIS 105 (Suppl. 68): 5-33.

Locksley RM, Heinzel FP, Sadick MD, Holaday BJ, Gardner Jr KD 1987. Murine cutaneous leishmaniasis: susceptibility correlates with differential expansion of helper T-cell subsets. Ann Inst Pasteur/ Immunol 138: 744-749.

Lowry OH, Rosebrough NJ, Farr AL, Randall RJ 1951. Protein measurement with the folin phenol reagent. J Biol Chem 193: 265-275.

Marsden P 1985. Pentavalent antimonials: old drugs for new diseases. Rev Soc Bras Med Trop 18: 187-187.

Mattner F, Magram J, Ferrante J, Launois P, Di Padova K, Behin R, Gately MK, Louis JA, Alber G 1996. Genetically resistant mice lacking interleukin-12 are susceptible to infection with Leishmania major and mount a polarized Th2 cell response. Eur J Immunol 26: 1553-1559.

Mayrink W, Antunes CMF, da Costa CA, Melo MN, Dias M, Michalick MSM, Magalhães P, Oliveira Lima A, Williams P. 1986. Further trials of a vaccine against American cutaneous leishmaniasis. Trans R Soc Trop Med Hyg 80: 1001.

Mayrink W, da Costa CA, Magalhães PA, Melo MN, Dias M, Oliveira Lima A, Michalick MS, Williams $P$ 1979. A field trial of a vaccine against American dermal leishmaniasis. Trans $\mathrm{R}$ Soc Trop Med Hyg 73: 385-387.

Mayrink W, Magalhães PA, Michalick MSM, da Costa CA, Oliveira Lima A, Melo MN, Toledo VPCP, Nascimento E, Dias M, Genaro O, Hermeto MV, Williams P 1992. Immunotherapy as a treatment of American cutaneous leishmaniasis: preliminary studies in Brazil. Parassitologia 34: 159-165.

Mayrink W, Michalick MSM, Melo MN, Williams P, Nascimento E, Magalhães PA, da Costa CA, Oliveira Lima A, Dias M 1991. Tratamento da leishmaniose tegumentar americana utilizando vacina. An Bras Dermatol 66: 55-59.

Mayrink W, Williams P, Magalhães PA, Melo MN, Dias M, Oliveira Lima A, Michalick MSM, Ferreira Carvalho E, Barros GC, Sessa PA, Alencar JTA 1985. An experimental vaccine against American dermal leishmaniasis: experience in the state of Espírito Santo, Brazil. Ann Trop Med Parasitol 79: 259-269.

Melby PC, Andrade-Narvaez FJ, Darnell BJ, ValenciaPacheco G, Tryon VV, Palomo-Cetina A 1994. Increased expression of pro-inflammatory cytokines in chronic lesions of human cutaneous leishmaniasis. Infect Immun 62: 837-842.
Mendonça SC, Coutinho SG, Amendoeira RR, Marzochi MCA, Pirmez C 1986. Human cutaneous leishmaniasis (Leishmania b. braziliensis) in Brazil: lymphoproliferative responses and influence of therapy. Clin Exp Immunol 64: 269-276.

Mendonça SCF, de Luca PM, Mayrink W, Restom TG, Conceição-Silva F, da Cruz AM, Bertho AL, da Costa CA, Genaro O, Toledo VPCP, Coutinho SG 1995. Characterization of human T lymphocytemediated immune responses induced by a vaccine against American tegumentary leishmaniasis. Am J Trop Med Hyg 53: 195-201.

Mosmann TR, Moore KW 1991. The role of IL-10 in crossregulation of TH1 and TH2 responses. Immunol Today: A49-A53.

Murray HW, Oca MJ, Granger AM, Schreiber, RD 1989. Requirement for $\mathrm{T}$ cells and effect of lymphokines in successful chemotherapy for an intracellular infection. Experimental visceral leishmaniasis. J Clin Invest 83: 1253-1257.

Nabors GS, Afonso LCC, Farrell JP, Scott P 1995. Switch from a type 2 to a type $1 \mathrm{~T}$ helper cell response and cure of established Leishmania major infection in mice is induced by combined therapy with interleukin 12 and Pentostam. Proc Natl Acad Sci USA 92: 3142-3146.

Nascimento E, Mayrink W, da Costa CA, Michalick MSM, Melo MN, Barros GC, Dias M, Antunes CMF, Lima MS, Taboada DC, Liu TY 1990. Vaccination of humans against cutaneous leishmaniasis: cellular and humoral immune responses. Infect Immun 58: 2198-2203.

Peters BS, Fish D, Golden R, Evans DA, Bryceson AD, Pinching AJ 1990. Visceral leishmaniasis in HIV infection and AIDS: clinical features and response to therapy. $Q \mathrm{~J}$ Med 77: 1101-1111.

Prussin C, Metcalfe DD 1995. Detection of intracytoplasmic cytokine using flow cytometry and directly conjugated anti-cytokine antibodies. J Immunol Methods 188: 117-128.

Ribeiro-de-Jesus A, Almeida RP, Lessa H, Bacellar O, Carvalho EM 1998. Cytokine profile and pathology in human leishmaniasis. Braz J Med Biol Res 31: 143-148.

Scharton TM, Scott P 1993. Natural killer cells as a source of interferon- $\gamma$ that drives differentiation of $\mathrm{CD}^{+} \mathrm{T}$ cells subsets and induces early resistance to Leishmania major in mice. J Exp Med 178: 567577.

Scott P 1989. The role of TH1 and TH2 cells in experimental cutaneous leishmaniasis. Exp Parasitol 68: 369-372.

Scott P 1991. IFN- $\gamma$ modulates the early development of Th1 and Th2 responses in a murine model of cutaneous leishmaniasis. J Immunol 147: 3149-3155.

Scott P, Trinchieri G 1995. The role of natural killer cells in host-parasite interactions. Curr Opinion Immunol 7: 34-40.

WHO - World Health Organization 1990. Control of the leishmaniases. Report of a WHO Expert Committee. WHO Tech Rep Ser 793: 1-158. 